\title{
Successful 36 Months Result of Debranching TEVAR for Kommerell's Diverticulm with the Aberrant Left Subclavian Artery
}

\author{
Hideaki Takai*, Satoshi Kawaguchi, Tsuyoshi Yamabe and Hiroaki Tanabe
}

Department of Cardiovascular Surgery, The Cardiovascular Institute, Nishiazabu Minato-ku, Tokyo, Japan

\begin{abstract}
A case of successful endovascular repair of right aortic arch with the aberrant left subclavian artery (ALSA) arising from Kommerell's diverticulum (KD). Our strategy consisted of coil embolization for the orifice of the ALSA, put the bypass between left common carotid artery and left subclavian artery and exclusion of KD by stent graft insertion. Enhanced computed tomography scan 36 months after the operation showed successful exclusion of KD, patency of the bypass graft, and no evidence of endoleak.

Endovascular repair can be a safe and effective treatment for aortic disease with challenging anatomy in the midterm, avoiding the need for a complex open surgery procedure. It is very rare in this successful case with midterm result we presented.
\end{abstract}

Keywords: Debranching TEVAR; Kommerell's diverticulum; The aberrant left subclavian artery

\section{Introduction}

Surgery for Kommerell's diverticulum is said to be difficult due to typical anatomical findings. Recently endovascular therapy became widely common, it contributed to the less invasive therapy. Now we had successful surgical case using stentgraft insertion for the Kommerell's diverticulum with the left aberrant subclavian artery in right aortic arch patient with 36-month follow up.

\section{Case Report}

A 54-year-old man was admitted to our department because of an abnormal shadow in the upper mediastinum, suggestive of the thoracic aortic aneurysm.

Computed tomographic (CT) scan demonstrated anomalies of the thoracic aorta and great vessels consistent with a right-sided and the aberrant left subclavian artery (ALSA) originating from the descending thoracic aorta (Figure 1). A focal dilatation was noted at the ALSA origin (diameter was $58 \mathrm{~mm}$ ), indicating Kommerell's diverticulum (KD). Due to the size of the KD and the potential for rupture, the patient elected to undergo Debranching TEVAR with a left common carotid artery - the ALSA bypass using $6 \mathrm{~mm}$ ePTFE graft.

\section{Operation}

Under the general anesthesia, operation was started at the spine position. At first he underwent the extra-anatomical bypass between the ALSA and the left common carotid artery using $6 \mathrm{~mm}$ ePTFE graft. Through a cutdown on the right common femoral artery, a $10 \mathrm{~F}$ sheath was inserted. A hydrophilic 0.035 -inch guidewire (Terumo Medical Corp, Tokyo, Japan) was advanced into the ascending aorta, and a wire exchange was made for a 0.035 -inch Lunderquist wire (Cook-Europe, Bjaeverskov, Denmark) through a pigtail catheter. Through the femoral access, a Cook Zenith TX2 endovascular graft (ZTEG 36-152-PF and 36-127-PF; Cook, Bloomington, IN, USA) was used for the thoracic aortic aneurysm with an overlapping of two stents between endografts. From the left brachial artery, several Interlocking Detachable Coils (Boston Scientific Japan, Tokyo, Japan) were deployed in the orifice of the ALSA just below the origin of the left vertebral artery. A completion angiography showed the excellent apposition to the vessel wall and the complete exclusion of the aneurysm and KD with no endoleaks.

\section{Post operative course}

The patient had no postoperative complications and was discharged 7 days later. He remained asymptomatic with symmetric upper extremity blood pressures during 36-month follow-up. The CT scan follow-up, performed at 1, 6, 12, 24 and 36 months, showed complete exclusion of the aneurysm and no evidence of endoleak (Figure 2).

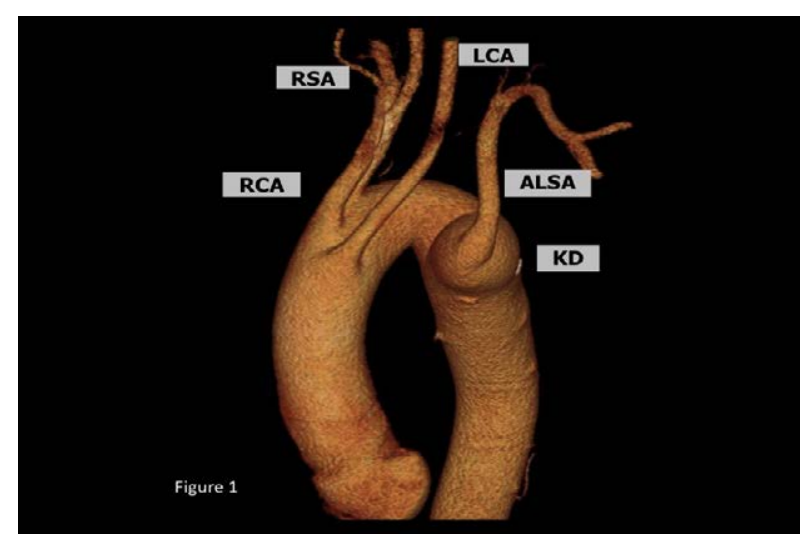

Figure 1: Preoperative 3D-CT scan is showed. The aberrant left subclavian artery arises from Kommerell's diverticulum.

*Corresponding author: Hideaki Takai MD, PhD, Department of Cardiovascular Surgery, The Cardiovascular Institute, Nishiazabu Minato-ku, Tokyo, Japan-106-0031; Telephone: +81-3-3408-2151; Fax: +81-3-3408-2159; E-mail: h-takai@cvi.or.jp

Received May 12, 2015; Accepted June 13, 2015; Published June 15, 2015

Citation: Takai H, Kawaguchi S, Yamabe T, Tanabe H (2015) Successful 36 Months Result of Debranching TEVAR for Kommerell's Diverticulm with the Aberrant Left Subclavian Artery. J Vasc Med Surg 3: 203. doi:10.4172/2329-6925.1000203

Copyright: ( 2015 Takai H, et al. This is an open-access article distributed under the terms of the Creative Commons Attribution License, which permits unrestricted use, distribution, and reproduction in any medium, provided the original author and source are credited. 
Citation: Takai H, Kawaguchi S, Yamabe T, Tanabe H (2015) Successful 36 Months Result of Debranching TEVAR for Kommerell's Diverticulm with the Aberrant Left Subclavian Artery. J Vasc Med Surg 3: 203. doi:10.4172/2329-6925.1000203

Page 2 of 2

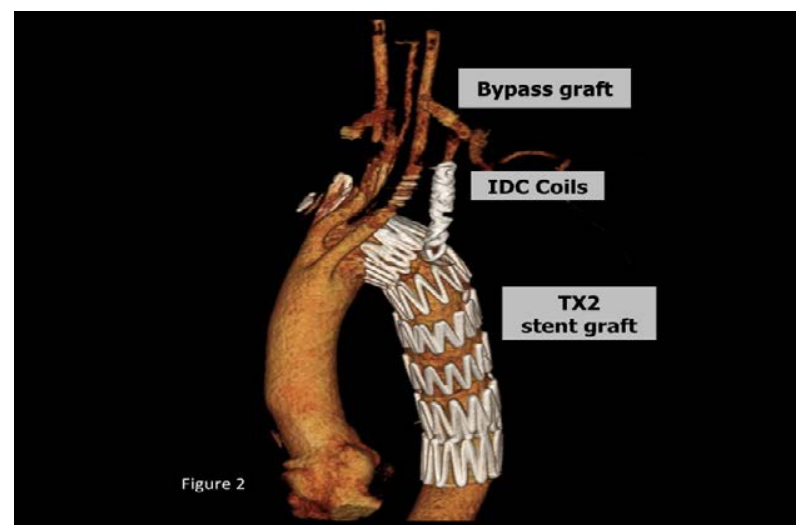

Figure 2: Postoperative 3D-CT scan is showed. 2 pieces of TX2 stentgrafts were inserted sequentially and IDC coils were inserted into the origin of the aberrant left subclavian artery. No endoleak was observed.

\section{Discussion}

Kommerel described first as an abnormality of anatomy (called as "Kommerel diverticulum") in thoracic right arch aorta with the aberrant right subclavian artery originating from the descending aorta in 1936 [1]. The right aortic arch with ALSA alone as an isolated anomaly is extremely rare.

It was said to the average size at aneurysmal rupture was $5.8 \mathrm{~cm}$, but the range was wide which might to be rupture [2,3]. In TEVAR therapy, the presence of the ALSA requires coil embolization to prevent a type II endoleak. Although endovascular deployment of an occluder was a simple and safe method, we could not use these commercial devices in Japan. LSA coverage is often necessary to perform proximal seal in up to $40 \%$ of patients treated with TEVAR $[4,5]$. In our case we performed coil embolization to prevent type II endoleak and bypass between left common carotid artery and left subclavian artery with 6 mm ePTFE graft because of the hypo-plastic left vertebral artery and his dominant was the left. In addition his occupation is truck driver, so revascularization for the ALSA was needed to prevent the left arm claudication. To our knowledge, only few cases of TEVAR of this type of pathology were reported. Okada [6] first demonstrated the feasibility of endovascular repair as well as other authors, performing mostly hybrid procedures $[7,8]$. Only in 2 cases, a total endovascular procedure $[9,10]$, confirmed that TEVAR is a viable and safe alternative to open surgical repair in these rare and complex cases. Indication of endovascular treatment might not to be recommended due to the lack of long-term results, as well as in hybrid repair [11,12]. Although some papers were published with the short-term result, now we presented good mid-term result in endovascular repair in KD with the ALSA.

\section{Conclusion}

Endovascular treatment of right-sided aortic arch aneurysms with ALSA can be made safely and effectively. The patients have not suffered from a postoperative aortic event, Debranching TEVAR might be a viable and safe alternative in the mid-term result to open surgical repair in these rare and complex cases.

\section{References}

1. Kommerell B (1936) Verlagerung des Oesophagus durch eine abnorm verlaufende Arteria subclavia dextra (Arteria Lusoria). Fortschr Geb Roentgenstr 54: 590-595.

2. Riesenman PJ, Campbell CL, Farber MA (2009) Endovascular repair of a Kommerell's diverticulum in a patient with a left-sided aortic arch and rightsided descending thoracic aorta. J Vasc Surg 49: 1577-1579.

3. Cinà CS, Althani $H$, Pasenau J, Abouzahr L (2004) Kommerell's diverticulum and right-sided aortic arch: A cohort study and review of the literature. J Vasc Surg 39: 131-139.

4. Dexter D, Maldonado TS (2012) Left subclavian artery coverage during TEVAR: is revascularization necessary? J Cardiovasc Surg 53: 135-141.

5. Weigang E, Parker JA, Czerny M, Lonn L, Bonser RS, et al (2011) Should intentional endovascular stent-graft coverage of the left subclavian artery be preceded by prophylactic revascularization? Eur J Cardiothorac Surg 40: 858868.

6. Okada K, Sueda T, Orihashi K, Watari M, Naito A (2001) Endovascular stentgraft repair for thoracic aortic aneurysm associated with right-sided aortic arch J Thorac Cardiovasc Surg 122: 185-186.

7. Naoum JJ, Parenti LJ, LeMaire SA, Coselli JS (2008) Endovascular repair of a right-sided descending thoracic aortic aneurysm with a right-sided aortic arch and aberrant left subclavian artery. Ann Thorac Surg 85: 1074-1076.

8. Frigatti $P$, Grego F, Deriu GP, Lepidi S (2009) Hybrid endovascular treatment of aneurysm degeneration in a rare right-aortic arch anomaly with Kommerell diverticulum. J Vasc Surg 50: 903-906.

9. Midorikawa H, Kannno M, Ishikawa K, Takano T, Ono T, et al. (2009) Endovascular repair of a Kommerell's diverticulum and aneurysmal right-sided aortic arch: A case report. Ann Vasc Dis 2: 54-57.

10. Silveira PG, Franklin RN, Cunha JR, Neves TT, Nascimento GG, et al. (2013) Total endovascular repair of aberrant left subclavian artery with Kommerell's diverticulum using a customized branched device. J Vasc Surg 57: 1123-1125.

11. Idrees J, Keshavamurthy S, Subramanian S, Clair DG, Svensson LG et al (2014) Hybrid repair of Kommerell diverticulum. J Thorac Cardiovasc Surg 147: 973-976.

12. Tanaka A, Milner R, Ota T (2015) Kommerell's diverticulum in the current era: A comprehensive review. Gen Thorac Cardiovasc Surg 63: 245-259. 